\title{
FutureJournal
}

Revista oficial do programa de Mestrado Profissional em Gestão de Negócios do Profuturo - Programa de Estudos do Futuro - da FIA BUSINESS SCHOOL

Editora Científica: Renata Giovinazzo Spers

Editor Internacional: James Terence Coulter Wright

Avaliação: Double Blind Review, pelo SEER/OJS

Revisão: Gramática, normativa e de layout

Recebido em: 07/02/2017 Aprovado em: 10/08/2017

\section{Contribuições do Marketing na Integração Economia Compartilhada e Estratégia}

\author{
Carlos Henrique Távora Pereira \\ Universidade de Fortaleza, Unifor, Brasil \\ chtpereira@hotmail.com \\ Minelle E. Silva \\ Universidade de Fortaleza, Unifor, Brasil \\ minele.adm@gmail.com
}

\section{RESUMO}

No contexto emergente de uma nova realidade chamada economia compartilhada, que se baseia em fatores tecnológicos, econômicos e sociais, a administração precisa identificar novos caminhos. Com isso, marketing e estratégia são algumas das áreas que emergem como contributivas neste novo contexto. Entende-se que contribuições da estratégia apontam para a construção de valor socialmente compartilhado entre agentes da sociedade. Todavia, questiona-se: como promover o marketing como instrumento integrador $\mathrm{da}$ estratégia com a economia compartilhada. No presente ensaio teórico, assume-se tal fato como ponto central de reflexão e buscase, por meio da construção de elos entre a estratégia e a economia compartilhada, salientar quais caminhos podem ser traçados no contexto do marketing, uma vez que este serve como canal entre as empresas e a sociedade. Alguns insights surgem ao longo da discussão e identifica-se que, por exemplo, o marketing colaborativo assume um papel de destaque nesta integração. Assim, estimulam-se reflexões ainda não realizadas na área, demonstrando o potencial da economia compartilhada no campo da administração.

PALAVRAS-CHAVE: Marketing. Economia compartilhada. Estratégia. Visão baseada em recursos. 


\section{Marketing Contributions to Integrate Sharing Economy and Strategy}

\section{ABSTRACT}

Based on a new reality called sharing economy which assume as necessary technological, economic and social factors, the field of Business needs new paths. Marketing and Strategy are some of these areas. There are contributions of the strategy to the socially constructed value shared among different social actors. However, it is questioned: how to promote marketing as an integrating instrument of the strategy and sharing economy? The current theoretical essay assumes the integration as a central aspect of reflection and search through the construction of links between the strategy and the sharing economy, to highlight which paths can be traced in the marketing context, since this is as a channel between the companies and society. There are some insights throughout the discussion and it is identified that, for example, collaborative marketing plays a prominent role in this integration. Thus, this discussion stimulates reflections regarding sharing economy, which is still scarce in the business administration area.

KEY-WORDS: Marketing. Sharing economy. Strategy. Resource-based view. 


\section{INTRODUÇÃo}

No campo da estratégia empresarial, diversos estudos trazem como tema central de sua discussão a busca pela vantagem competitiva (VC) (Porter \& Kramer, 2011; Srivastava, Fahey \& Christensen, 2014). Desse modo, existem várias formas de concepção e execução da estratégia que convergem para o objetivo central de garantir que as empresas detenham VC, graças à sua capacidade de gerar valor (Barney, 2007). Ocorre que, na atualidade, quando a dinâmica social é observada com um grau de complexidade sem precedente (Martin, 2016; Rifkin, 2016), ganha escala um fenômeno cuja emergência data da década de 1990, nos Estados Unidos, graças a fatores sociais, econômicos e tecnológicos. Esse fenômeno procura atender à busca por um novo conceito de valor e uma postura de consumo baseada na ideia do compartilhamento (Schor, 2014). Trata-se da economia compartilhada (EC), também observada como um modelo de negócio no qual a propriedade e o acesso são compartilhados entre corporações e pessoas (Owyang, Tran \& Silva, 2014).

Há, então, duas realidades coexistindo, a saber: (1) a dinâmica empresarial representada pela estratégia e (2) a dinâmica social e econômica prevista pela economia compartilhada. Concebidos tais elementos e identificada uma lacuna entre eles, torna-se necessário o desenvolvimento de uma discussão que promova uma conexão entre os conceitos destacados. Assim, construiu-se esta discussão cujo fim é promover uma reflexão teórica contributiva acerca da questão: como promover o marketing como instrumento integrador da estratégia com a economia compartilhada?

Busca-se neste estudo estreitar a relação entre o campo da estratégia à luz da visão baseada em recursos (VBR) e a EC, utilizando o marketing como ponte conceitual, dada sua propriedade de servir de canal entre empresas e sociedade. Objetiva-se aprimorar esta integração de forma reflexiva e interpretativa, como sugere Meneghetti (2011), fazendo uso de um ensaio teórico. Para tanto, construiu-se uma relação intersubjetiva de construtos (Meneghetti, 2011; Boava, Macedo \& Sette, 
2012) que, promovida a partir de uma bagagem de conceitos e experiências, vivencia, no ensaio uma reflexão (Bertero, 2011).

Reitera-se o uso de um ensaio teórico pelo interesse claro de gerar questionamentos sobre o tema e não uma única resposta e, ainda, pelo anseio de publicitar a perspectiva dos autores. Segundo Meneghetti (2011), neste exercício de construção do conhecimento considerado científico, é permitido inserir fragmentos de pensamentos, reflexões parciais ou totais. Exploram-se tais inserções com elementos do marketing capazes de contribuir para a compreensão da realidade que edifica o elo entre 0 conhecimento existente e o novo.

Mesmo não se tratando de uma revisão teórica, visto que busca o novo, o ensaio é construído expondo conceitos (Meneghetti, 2011; Boava et al., 2012). Então, sem procurar exauri-los, serão apresentados os conceitos fundamentais dos construtos que compõem este estudo: (1) a estratégia com ênfase na VBR, (2) a economia compartilhada e (3) o marketing como elemento integrador dos construtos anteriores. Com isso, busca-se no desenvolvimento desta reflexão identificar e ressaltar quais as contribuições a área de marketing pode trazer para a relação identificada e, então, gerar insights para que novas pesquisas possam ser desenvolvidas na área.

\section{A ESTRATÉgIA E A NOVA PERSPECTIVA DO VALOR SOCIALMENTE COMPARTILHADO}

O ambiente empresarial é continuamente caracterizado pela competição entre empresas. Um dos principais objetivos do pensamento estratégico traduz-se na obtenção de performance superior, que está integrada com o conceito de vantagem competitiva e valor, não cabendo dissociá-los. A VC, que faz parte da evolução do pensamento estratégico, tornou-se multidimensional e não se concebe mais mensurar a sua obtenção utilizando, unicamente, medidas monetárias. Novas dimensões ganham destaque, cabendo às empresas sustentarem sua VC na ótica econômica, social e ambiental do negócio. Essa configuração é fruto de um processo evolutivo, uma adequação à nova realidade que envolve muitos agentes econômicos (Jannesson, Nilsson \& Rapp, 2014). 
Desde a década de 1970, as abordagens da estratégia concernentes à VC são alocadas em quatro eixos (Vasconcelos \& Cyrino, 2000): (1) como atributo de posicionamento (explica-se por fatores externos), (2) como atributo de performance (explica-se por fatores internos), (3) como processos de mercado (explica-se por fatores externos) e (4) como capacidades dinâmicas (explica-se por fatores internos). Então, uma nova conjuntura é estabelecida nos mercados, composta por ambientes com alto grau de incerteza, maiores índices de complexidade, cuja concepção de recursos e competências sofre atualizações. Com base nessa evolução, observa-se uma tendência a valorizar o processo de aprendizagem baseado em fatores internos e externos, associado à inovação e, logo, à capacidade de gerir mudanças.

Um conjunto de contribuições às discussões sobre VC é postulado na dinâmica do mercado e da concorrência, em que ambos estão longe de ser caracterizados pelo equilíbrio, mas são consequência de descobertas interativas e conhecimentos dispersos (Kirzner, 1985). O lucro resulta da descoberta de novas oportunidades e da criação de novas combinações, descritas por Schumpeter (1934) com a expressão "destruição criativa". A dinâmica competitiva fomenta a descoberta e influencia a performance das empresas estimulando a concepção de diferentes alternativas de valor. 0 termo "dinâmico" assemelha-se à capacidade de renovar as competências em congruência com os sistemas que acomodam os diferentes negócios (Teece, 2009).

Torna-se relevante refletir sobre abordagens da estratégia que exploram de forma mais eminente elementos tais como os recursos, processos de mercado e capacidades dinâmicas, isto é, a VBR. Nos anos de 1990, a VBR ganha força ao explicar a distinção entre empresas a partir de suas forças individuais, tentando elucidar a forma de obter o melhor desempenho (Collis \& Montgomery, 1995). Baseada nos trabalhos de Edith Penrose (1959), com destaque para o "The theory of the growth of the firm", essa linha de pensamento julga ser impossível avaliar o sucesso das empresas exclusivamente pelos efeitos promovidos pelo ambiente além dos limites das empresas. Cita Penrose (1959, p. 42): "[...] exceto dentro dos limites mais amplos, nós não podemos explicar, adequadamente, o 
comportamento da empresa ou prever a probabilidade de sucesso ao examinar, meramente, a natureza das condições ambientais".

Contrária à análise da época, emerge uma linha que mira nos recursos internos para melhor entender as condições que justificariam a construção de uma maior VC. Kretzer e Menezes (2006) afirmam que muitos estudiosos como Jay Barney, Margaret A. Peteraf, Ingemar Dierickx e Karel Cool, David Teece podem ser citados como apreciadores desta tratativa que trabalha a interação entre recursos e estratégia empresarial. Para Foss e Langlois (1997), empiricamente, a estrutura fundamental da VBR analisa a VC partindo de duas premissas: (1) existem diferenças assimétricas entre as empresas, isto é, as empresas apresentam uma heterogeneidade; e (2) tais diferenças são relativamente estáveis, coexistem com a propriedade da imobilidade.

Fundamentada nesses preceitos empíricos, alicerça-se a base teórica da VBR, partindo da ideia de que os diferentes recursos das empresas justificam diferentes desempenhos, maximizando seus desempenhos econômicos. Empresas possuirão desempenho superior graças ao que elas possuem em especial, com destaque aos recursos que Ihes atribuem exclusividade, habilitando-as a gerar valor de forma única e de tal maneira que seja difícil de ser reproduzido ou copiado pelos concorrentes (Prahalad \& Hamel, 1990; Kretzer \& Menezes, 2006).

Tais "recursos" apresentam-se como bens, ativos tangíveis e intangíveis, processos organizacionais, atributos, informações, conhecimentos que estão vinculados à empresa e lhe permitem pôr em prática sua estratégia. Diferentes tipologias são utilizadas. Para Barney e Hesterly (2007), recursos podem ser classificados em capital físico (tecnologia, fábricas e equipamentos, localização geográfica, acesso às matérias-primas, etc.), humano (gestores e colaboradores, treinamento, experiência, cultura e conhecimento) e organizacional (relatórios, planejamentos, controles e sistemas, processos e rotinas representando suas capacidades). Grant (1991) acrescenta ao portfólio de recursos o capital financeiro e o capital reputacional.

Adicionalmente, Prahalad e Hamel (1990) afirmam que capacidades ou "competências" poderão ser estratégicas e centrais em determinados 
negócios, sendo consideradas, nestes casos, competências essenciais (core competences). Entende-se como capacidades dinâmicas a propriedade de explorar competências internas e externas, que potencializam a renovação das próprias competências em um mercado em mudança. A essência das capacidades dinâmicas está nos processos organizacionais moldados a partir de seus ativos (posições) e seu caminho evolutivo, tornando-os tácitos path dependence (Grant, 1991; Leite \& Porsse, 2003).

Os recursos e as capacidades mais importantes serão duráveis, difíceis de identificar e entender, imperfeitamente transferíveis, difíceis de reproduzir e sobre os quais a empresa possui clara posse e controle, estando a essência da formulação da estratégia centrada na sua melhor utilização (Grant, 1991). A conquista de VC vai além da correta utilização dos recursos e das capacidades dinâmicas, está na renovação e criação de novos recursos e capacidades (Collis \& Montgomery, 1995; Teece, 2009) ou na combinação coordenada de habilidades e de recursos essenciais e dinâmicos, capazes de construir, manter e potencializar vantagens que potencializem valor.

Próximo ao debate sobre VC, um novo propósito empresarial é redefinido a partir da geração de valor compartilhado. Surge, então, um movimento favorável à construção de valor econômico a partir do atendimento do valor social. Não se trata de caridade ou filantropia, mas de um conceito de VC social, uma nova estratégia direcionada à obtenção de um posicionamento único, capaz de gerar valor compartilhado (Porter \& Kramer, 2011). Esse debate também pode ser realizado de acordo com a visão de responsabilidade social, que surge como uma vantagem competitiva (Sousa Filho et al., 2010; Silva \& Balbino, 2013). Tal perspectiva recebe influência direta do debate sobre recursos e capacidades e precisa ser observado no contexto atual de mudanças na sociedade.

$\mathrm{Na}$ VBR, tal debate sobre valor não é isento de questionamentos podendo ser visto como uma caixa-preta, principalmente, no que se refere ao processo de transformação de recursos em algo valioso para o cliente (Srivastava et al., 2014). Tem-se que o conhecimento dos agentes de mercado como clientes, fornecedores, canais e concorrentes são insumos para a construção dos processos organizacionais (Day, 1992). A busca pelo 
novo valor cresce quando as empresas alinham inovação com utilidade, e a utilidade social ganha força. Busca-se acelerar a compreensão de valor social compartilhado e isso provoca o surgimento de novos modelos de negócio. Emerge, então, uma alternativa moldada a partir da união entre empresas e demais agentes da sociedade, a economia compartilhada.

\section{ECONOMIA COMPARTILHADA (EC)}

O compartilhamento é um fenômeno que nasce juntamente com a humanidade, enquanto o consumo compartilhado surge com o acesso à internet (Belk, 2014). A EC é vista por alguns autores como uma nova configuração do capitalismo (Gansky, 2011; Chase, 2015; Rifkin, 2016; Frenken, 2017), por tratar-se de um tema construído a partir de múltiplas visões, por esse motivo, é apresentada a partir de diferentes abordagens (Allen, 2014; Burnett, 2014; Novel \& Demailly, 2014), como mesh (Gansky, 2011), consumo colaborativo (Botsman \& Rogers, 2011; Belk, 2014), economia colaborativa (Owyang et al., 2014) ou consumo conectado (Dubois, Schor \& Carfagna, 2014).

Apesar de inexistir uniformidade no seu tratamento, é uníssona a crença de que a EC, como se observa hoje, surge da combinação de três fatores (Botsman \& Rogers, 2011; Schor, 2014; Olson \& Kemp, 2015), expostos aqui sob a ótica da consultoria Altimeter (Owyang et al., 2014): (1) sociais: aumento da densidade populacional, busca pela sustentabilidade, desejos comunitários e altruísmo; (2) econômicos: maior flexibilidade de financiamentos, acesso mais valorizado que a posse, monetização de ativos ociosos e migração de investimentos para projetos colaborativos; (3) tecnológicos: expansão das redes sociais, disseminação da mobilidade por meio de aparelhos inteligentes e conectados e aprimoramento do sistema de pagamento via WEB.

Diante da não uniformização do conceito e com o propósito de facilitar a condução deste estudo, será explorada a abordagem proposta por Heinrichs (2013), na qual a EC é tratada como um "conceito guarda-chuva", que sumariza os elementos-chave do debate. Isto é, aceita-se como EC todo conteúdo pertinente à economia compartilhada e os demais 
concernentes ao consumo colaborativo e à economia colaborativa, não cabendo, neste ensaio, dissociá-los. Tal fato se justifica ainda, porque, segundo Silveira, Petrini e Santos (2016), a temática que engloba todos esses conceitos não está madura, o que exige diversas outras pesquisas.

Maurer, Figueiró, Pacheco, Silva e Barcellos (2015) citam que o conceito de consumo colaborativo foi descrito pela primeira vez por Algar (2007) como sendo a prática da partilha, empréstimos comerciais, aluguel e trocas, transportadas para o século XXI. Esse conceito é ampliado por Botsman e Rogers (2011), como sendo a prática que permite o acesso a bens e serviços sem que, obrigatoriamente, ocorra aquisição de um produto ou transação monetária entre as partes envolvidas. Trata-se de uma reinvenção da tradicional forma de atuar no mercado, não possível antes do advento tecnológico. Owyang et al. (2014) define economia colaborativa como um modelo econômico no qual a propriedade e o acesso são compartilhados entre empresas, startups e pessoas.

Segundo Gansky (2011), a EC é um sistema socioeconômico alicerçado no compartilhamento de recursos humanos e físicos, incluindo criação, produção, comércio, distribuição e consumo na forma de compartilhamento de bens e serviços entre pessoas e organizações. A EC envolve o compartilhamento de ativos tangíveis e intangíveis (Belk, 2014), reduz intermediários e aprimora as conexões diretas entre os agentes, caracterizando-se como uma nova modalidade de negócio não tratada na economia tradicional (Dubois et al., 2014). Botsman e Rogers (2011) define EC como um sistema econômico baseado no compartilhamento de serviços ou bens ociosos, podendo ocorrer gratuitamente ou não, sem a participação de intermediários.

Assim, assume-se economia compartilhada como um sistema econômico e social que permite o acesso compartilhado a bens, serviços, dados e talentos; um modelo de mercado híbrido (entre posse e doação) de transações entre pares, frequentemente fomentado por meio de plataformas digitais. Esse sistema apresenta-se sob uma variedade de formas, mas toda a tecnologia da informação permite a distribuição, o compartilhamento e a reutilização de excessos de capacidade de bens e serviços (Heinrichs, 2013). Sobre suas formas, corroboram Botsman e 
Rogers (2011) afirmando que diferentes modalidades de transação estão presentes na EC: compartilhamento, empréstimo, aluguel, doação, trocas e, até mesmo, escambo.

Inexiste, também, uniformização acerca da nomenclatura utilizada no tratamento dos agentes econômicos envoltos na prática da economia compartilhada. Segundo Schor (2014), as empresas são chamadas de business (negócios), e as pessoas físicas de peers (pares). Na EC compartilhada, é possível apresentar as empresas (pessoas jurídicas) como peers Inc. e as pessoas físicas simplesmente como peers (Chase, 2015).

Inexistem restrições para que pessoas jurídicas e físicas atuem em diferentes papéis, como fornecedoras de produtos ou serviços, fomentadoras de mercado ou provedoras de plataforma (Krupinsk, 2016). Por essa razão, a depender da orientação, é possível verificar tipos distintos de operação: par - par (peers to peers - P2P) ou empresa - par (business to peers - B2P). Apesar de configurarem negócios mais associados à economia convencional, observam-se na EC negócios empresa para empresa (business to business - B2B).

Nesse processo interativo, a perene troca de informações entre as partes de forma multidirecional potencializa a contínua geração de novas ofertas e gera valor aos envolvidos, dentre outras formas, pela troca de experiências, pela possibilidade de monetização de ativos ociosos, pela diversificação de fontes de renda e pela redução dos custos nas transações. O compartilhamento possibilita, ainda, a redução do custo marginal dos ativos (Fremstad, 2015; Olson \& Kemp, 2015; Rifkin, 2016; Sundararajan, 2016).

A EC é apontada como um movimento desenvolvedor de ciclos de confiança (Chase, 2015), visto que estimula o compartilhamento entre pessoas desconhecidas. A cotidiana prática da aplicação de feedbacks e avaliações nas plataformas digitais fomenta uma ambiência de segurança, na qual a reputação substitui a regulação (Viana, 2015). O processo de legitimação faz parte das interações sociais atreladas às relações de consumo e elementos como a cultura ganham força no ritual de consumo de ativos físicos e digitais (Sundararajan, 2016; Gregory \& Halff, 2017). 
É creditada às crises econômicas, com destaque àquelas vividas na última década, a criação de um processo de desconfiança no "antigo", isto é, conceitos ultrapassados, e uma coragem maior para acreditar naquilo que é novo, conceitos com novas abordagens (Botsman \& Rogers, 2011; Heinrichs, 2013; Schor, 2014; Rifkin, 2016). Observa-se na EC que seus agentes econômicos, mais especificamente os usuários, buscam reavaliar 0 que, de fato, é valioso. Isto é, buscam refletir sobre o "possuir" ou o "ter acesso". A EC cresce juntamente com o low consumerism, ou lowsumerism, baseado no princípio do consumo que se apoia em três atitudes: pensar sempre antes de comprar, buscar alternativas menos nocivas ao meio ambiente (consertar, compartilhar ou mesmo fabricar) e viver somente com o que, de fato, é necessário (Pugliese, 2015).

Ademais, atribui-se maior exposição e valor ao conceito de sustentabilidade, atendendo à sua tríplice abordagem: econômica, social e ambiental (Dubois et al., 2014). A EC é uma nova configuração mais preocupada em ser sustentável. Sua prática sugere o uso mais eficiente de recursos por meio de upcycling (Chase, 2015; Rifkin, 2016), exploração de ativos ociosos, diminuição do desperdício e redução de emissão de carbono graças ao compartilhamento de veículos (Schor, 2014). Estudos do Instituto de Desenvolvimento Sustentável e Relações Internacionais (IDDRI), de Paris, sugerem que, com uma boa gestão de bens compartilháveis, a produção do lixo doméstico seria reduzida na ordem de $20 \%$ e o orçamento das famílias, em $7 \%$.

A EC desenvolve-se com elevado grau tecnológico nas suas redes de informação e comunicação que medeiam os negócios. É necessária, pois, a presença de um elemento que viabilize e gerencie essa operação: a plataforma digital, cuja principal finalidade é possibilitar a aproximação entre recursos, capacidades e ativos excedentes e seus usuários. A plataforma organiza, padroniza e simplifica a participação das empresas e dos demais pares. É por meio das plataformas digitais que as transações são viabilizadas, liberando o valor dos excedentes (Chase, 2015; Herbert \& Collin-Lachaud, 2016). Elas atuam sob duas orientações de mercado, com e sem fins lucrativos, e propiciam a composição de um banco de dados com uma riqueza pouco observada nos modelos que as antecederam (Schor, 
2014). Finaliza-se destacando que a EC se apresenta como uma nova forma de interação social e econômica (Heinrichs, 2013), e, devido à sua relevância, torna-se oportuno um esforço que possibilite seu entendimento e a conexão com outros temas.

\section{MARKETING, ECONOMIA COMPARTILHADA E ESTRATÉGIA: INSIGHTS E CONTRIBUIÇÕES}

O marketing está profundamente associado à estratégia empresarial, sendo impossível dissociá-los. Não é mais uma função, mas uma atividade que, além de ser derivada da estratégia, alimenta sua concepção e sua execução. No que concerne à ligação entre o marketing e a estratégia, existem estudos que trabalham tal associação de forma mais dirigida, aplicando a VBR como referência no desenvolvimento da teoria do marketing ou, ainda, na avaliação dos desafios verificados na prática do marketing (Srivastava et al., 2014). Similarmente, o marketing estratégico lida fundamentalmente com os processos organizacionais, buscando atender aos anseios da estratégia (El-Ansary, 2006).

É preciso alinhar este exercício com as aspirações dos seus principais atores, por se tratar de um processo, essencialmente, social. Costumes, necessidades e hábitos dos consumidores mudam com o tempo, sob influência de acontecimentos sociais e econômicos. Transformações estruturais de cunho econômico e social foram decisivas no repensar de um novo modelo econômico (Silva, Aguiar, Falcão \& Costa, 2012). A estratégia e o marketing buscam atuar em consonância com as expressões sociais e, assim, acompanham os movimentos e anseios trazidos pela sociedade. Segundo Silva et al. (2012), o pensamento em relação ao marketing evolui seguindo as transformações sociais, de acordo com as interações que envolvem produção e consumo de bens e serviços.

Nesse contexto, sob a ótica das interações sociais, a geração de valor compartilhado e a prática da EC potencializam novas reflexões guiadas, por exemplo, pela triangulação com a VBR e o marketing. O marketing defende maior eficiência empresarial a partir da integração de processos. Segundo El-Ansary (2006), o foco do modelo de processo do 
marketing estratégico está na formulação, no reconhecimento do alvo, na diferenciação e no posicionamento estratégico para criar, comunicar e entregar valor.

Em 2013, o marketing ganha uma nova definição, que o apresenta como atividade, conjunto de instituições e processos para criar, comunicar, entregar e trocar ofertas que têm valor para clientes (customers), clientes, parceiros e sociedade em geral (AMA, n.d.). As empresas que desempenham o novo marketing, intitulado 3.0 (Kotler, Kartajaya \& Setiawan, 2010) oferecem uma contribuição maior em termos de missão, visão e valores e buscam soluções para questões da sociedade. É válido acreditar que esse processo será mais bem recebido pelos clientes tanto quanto maior for a sua participação na cadeia produtiva. Introduz-se aqui o termo cocriação, cunhado por Prahalad (Kotler et al., 2010), que atende com propriedade a este anseio.

$\mathrm{Na}$ perspectiva da VBR, essa contribuição externa insere-se no conceito de capacidade dinâmica, que caberia ser promovida internamente. $\mathrm{Na}$ EC, ganham força as capacidades dinâmicas geradas a partir da interação entre empresa e pares (clientes ou outras empresas). Logo, cabe às empresas explorarem, além das próprias capacidades dinâmicas, outras advindas de agentes externos. A EC estimula a crescente tendência de os consumidores avançarem nas suas capacidades criativas e colaborativas, exercendo um papel mais latente na geração de valor. O marketing colaborativo surge oportunamente como elemento que, conjugado com o marketing 3.0, é capaz de administrar a colaboração de pares de negócios (Kotler et al., 2010), por exemplo, na economia compartilhada.

O cliente que acredita no valor compartilhado, é preciso lembrar, busca ter sua demanda atendida a partir de uma postura mais socialmente responsável em diferentes aspectos (Porter, 2011; Morais Neto, Pereira \& Moritz, 2012; Silva et al., 2012). A construção de valor sob o olhar mais orientado para o social provoca o surgimento dos princípios que regem a vantagem competitiva compartilhada que, correlacionada com o fenômeno da EC, novamente, permite o uso da VBR como objeto da estratégia e do marketing como mediador. O marketing apresenta-se como uma 
alternativa, um canal de integração entre a empresa e o cliente que respira economia compartilhada.

Alinhados com a VBR, estudiosos contribuem apresentando diferentes dimensões de valor para o cliente na ótica do marketing (Kotler et al., 2010): atributos, benefícios, atitudes e benefícios de rede. Este último é facilmente enquadrado no ambiente da EC, dada sua forte presença nas redes sociais, com destaque às digitais. São criadas redes de entidades com distintos conhecimentos, habilidades e tecnologias e essa interação permite a reconfiguração de novos processos. A tecnologia tornou-se um elemento-chave que estimula e possibilita maior conectividade e interatividade, possibilitando a transformação dos consumidores em prosumidores (Kotler et al., 2010) e a expansão da economia compartilhada (Owyang et al., 2014).

O atendimento às expectativas da sociedade passa pela incorporação de novas soluções que atendam à premissa do valor compartilhado e socialmente responsável, traduzidas nas dimensões dos atributos, benefícios, atitudes e efeitos de rede. Kumar, Jones, Venkatesan e Leone (2011) apontam o marketing orientado para o mercado como alternativa. As empresas orientadas ao mercado podem, mais precisamente, exercer esse papel de identificação das necessidades da sociedade (Kumar et al., 2011) e, consequentemente, se tornarem mais habilitadas para interagir seguindo as premissas do consumo colaborativo, isto é, da economia compartilhada.

Essa orientação do marketing constrói elementos que geram ganhos, colaborando com a VBR, especificamente, no que diz respeito à construção das capacidades dinâmicas, quando reconhece um caminho longitudinal, um processo construtivo alicerçado no aprendizado social, denominado pela VBR como path dependence, no qual "a história importa" (Teece, Pisano \& Shuen, 1997). Drucker (1986) comunga desse pensamento quando cita que a intenção e o papel declarado do marketing é ver o mundo atual e, também, as potenciais novas leituras. É favorecido, assim, o entendimento de que o marketing pode atuar na integração das empresas no âmbito da EC. 
Concernente ao processo de criação de valor, a VBR estabelece a premissa de que tal exercício surge graças aos recursos e às competências que a empresa possui de forma distinta. Este segundo, entretanto, não ocorre de forma isolada. Portanto, se avaliado na ótica da VBR, o marketing pode ser tratado como uma capacidade dinâmica (Alves, 2016). Possui apelo evolutivo e acredita na geração de valor a partir de processos que se renovam. A teoria do aprendizado social interpreta que essa construção de conhecimento é reflexo de vários fatores, inclusive, do ambiente em que se encontram os agentes, podendo a mesma atuar de forma seletiva ou proativa, cativando dependências com "quem" e "como" eles interagem (Bandura, 1977).

O marketing apropria-se desta tese quando estimula maior integração e relacionamento entre todos os pares envolvidos. Em se tratando do elo entre a empresa e o mercado, e tratando o marketing como a ponte entre as partes, é importante que a colaboração seja maior que a competição, cabendo ao coletivo ser maior que o individual, sendo esta realidade devida na concepção e execução da estratégia (Toaldo \& Luce, 2006). Em outras palavras, o marketing pode ser utilizado como instrumento de fomento às relações previstas na EC.

Noutra perspectiva, observando-se o marketing de relacionamento, é possível articular oito instrumentos centrais (Che Wel \& Bojei, 2009): (1) senso de comunidade, (2) serviços ao cliente, (3) tratamento personalizado, (4) tratamento preferencial, (5) integração da comunidade, (6) customização, (7) premiações tangíveis e (8) comunicação pessoal. Logo, atribui-se ao marketing a propriedade de arregimentar relações e desencadear novas composições sociais, a saber, com forte apelo ao compartilhamento como, por exemplo, a cocriação, presente na economia compartilhada.

A capacidade de relacionamento e a cocriação não surgem passivamente, podendo haver dúvidas e preocupações no relacionamento, por exemplo, dos diversos intermediários, os canais de marketing que atuam como elo entre as empresas e os consumidores na EC. Na EC, as relações informais pautadas na confiança são mais importantes do que relações formais traduzidas em contratos (Sundararajan, 2016). Na 
temática normatização do relacionamento à luz do marketing, dois grupos de normas são citados (Paswan, Blankson \& Guzman, 2011): o que ajuda na criação de valor (solidariedade, mutualidade, flexibilidade, troca de informações, integridade, orientação de longo prazo, etc.) e o facilitador de reivindicações (comportamento de conflito, monitoramento e redução de poder e autonomia). É possível conceber esses canais como instrumentos de desenvolvimento de capacidades.

A força do marketing como mediador cresce à medida que os paradigmas dos processos relacionais migram de propriedade para relacionamento, de forte governança para processos interativos, de um mecanismo de governança hierárquica para um relacionamento horizontal e de uma visão estática para uma estrutura dinâmica (Paswan et al., 2011). Essa concepção está alinhada com a lógica do marketing corporativo, delineada por meio da importância dada à marca e à reputação das empresas, na perspectiva da visão baseada em identidade.

É possível identificar uma consistente relação entre o marketing e a responsabilidade social corporativa, elemento muito presente nos debates de criação de valor compartilhado (Morais Neto et al., 2012). Não detalhando essa proposição, é possível justificá-la observando uma das oito dimensões do marketing corporativo: a preocupação ética e social como seu princípio central (Balmer, 2011). Próximos às discussões sobre responsabilidade social e marketing, surgem tópicos associados a um tema mais amplo - a sustentabilidade -, que, similarmente, está presente no cotidiano da EC (Rifkin, 2016). Consequentemente, torna-se promissor fomentar um diálogo entre a EC, a sustentabilidade e o marketing.

Alinhado com a mudança observada nas interações sociais representadas aqui pela EC (Rifkin, 2016) e em resposta à nova concepção de valor baseada no atendimento às premissas sociais básicas, composto do valor compartilhado (Porter \& Kramer, 2011) e da responsabilidade social corporativa (Morais Neto et al., 2012), Jones, Clarke-Hill, Comfort e Hillier (2008) contribuem ao citar que os elementos consumo, marketing e sustentabilidade iniciam tratativas ricas em torno do equilíbrio de cada interesse. Tanto o marketing contribui com a sustentabilidade, como a sustentabilidade contribui com o marketing (Jones et al., 2008). 
Enfim, o campo da estratégia empresarial, no prisma da VBR, busca a conquista de valor concentrando esforços na eficiência do uso de ativos singulares e, em especial, de competências dinâmicas. Porém, em detrimento de uma nova ordem social, representada pela EC e pela percepção de um novo conceito de valor, o valor compartilhado, novos elementos são envolvidos nesta tratativa, tornando válida a promoção de maior integração. Na mesma direção, justificado por suas propriedades, o marketing torna-se uma disciplina que muito tem a contribuir com esta construção do novo em diferentes frentes, como proposto neste ensaio. São muitas as possibilidades e questões ainda sem respostas, contudo, bem maiores são os benefícios e os desdobramentos dessa triangulação.

\section{CONCLUSÕES}

A EC tem despertado curiosidade na comunidade acadêmica e empresarial em virtude da sua influência no campo da estratégia, tornandose oportuno estudar o estreitamento entre sua prática e as empresas. Após a apresentação da estratégia segundo a VBR e a EC, foi possível esboçar laços utilizando o marketing como elemento mediador, em função das propriedades que este último detém quando o assunto é conectar as empresas à sociedade.

Crê-se, ainda, que a EC possua dois fatores que merecem atenção especial: (1) a nova percepção de valor, concebida numa visão mais socialmente equilibrada e (2) a interação entre os agentes empresa e cliente, que extrapola os limites convencionais e carece de cuidados. No desenvolvimento deste ensaio, foi possível expor como o marketing apresenta elementos suficientemente capazes de lidar com tais configurações e detém formas particulares de atuação que atendem às premissas da EC.

Destacadamente, o marketing colaborativo trata este assunto com a devida preocupação, sendo válido como exemplo e um primeiro laço. O elo nasce na concepção da estratégia, quando o marketing estratégico conversa com a estratégia alimentando-a e sendo alimentado por ela. Ademais o marketing pode ser considerado como uma competência dinâmica nos 
conceitos da VBR, portando-se como ponte entre a estratégia e a EC, graças à sua perene contribuição alinhada à perspectiva evolucionária de valor.

A ênfase na ampla interação multidirecional e, também, na preocupação com o conceito de sustentabilidade, que trafega nas vias utilizadas pelos agentes da EC, é preenchida pelo marketing 3.0, que traz respostas na coparticipação, cocriação e apego ao que é concebido com a devida procura por uma postura mais sustentável. Novamente, ganha força a tese de que o marketing conduz a aproximação entre a estratégia e a economia compartilhada. É possível depreender que as alternativas previstas na orientação do marketing habilitam a estratégia a melhor se posicionar diante da EC. A capacidade de atuar com direcionamentos para e pelo mercado pactua com a característica dinâmica da EC. Os pares atuando como prosumidores reportam suas necessidades em ambos os sentidos.

Quando se admite que o preciosismo na comunicação entre os agentes é pactuado nas plataformas digitais da EC como verdadeiros canais e, simultaneamente, é conhecida a ampla possibilidade de troca de informações estratégicas por meios dos canais de marketing, é possível advogar em favor da leitura de que as plataformas são verdadeiros canais de marketing e, devidamente geridas, são ponte entre a estratégia e a EC nas suas variadas expressões.

Conclui-se, mesmo sem exaurir todas as derivações possíveis, que o marketing se apresenta como elemento conciliador e atenuador da distância entre a estratégia e a EC. As reflexões traçadas neste ensaio, ainda que elucidativas, carecem de desdobramentos que aprofundem novas questões que possuam relação com o tema. Logo, trata-se de um convite para o desenvolvimento de novas pesquisas, quando se abre uma porta que leva à ponte que o marketing edifica entre a estratégia e a EC. Tal convite suscita outras reflexões a depender do caminho pelo qual se opta para melhor compreender a estratégia guiada à luz da visão baseada em recursos e seu paralelo com a EC. 


\section{REFERÊNCIAS}

Algar, R. (2007). Collaborative consumption. Leisure Report. Recuperado em 01 de março, 2016, de http://www.oxygenconsulting.co.uk/insights/collaborative-consumption/

Allen, D., \& Berg, G. (2014). The sharing-economy. How over-regulation could destroy an economic revolution. Institute of Public Affairs, Australia.

Alves, C. A. (2016, janeiro/março). Capacidades de marketing e inovação organizacional: uma relação para vantagem competitiva. Revista Alcance [eletrônica], 23(1).

American Marketing Association - AMA. (n.d.). Definition of marketing. Recuperado em 10 de maio, 2016, de https://www.ama.org/AboutAMA/

Balmer, J. M. T. (2011). Corporate marketing myopia and the inexorable rise of a corporate marketing logic. European Journal of Marketing, 45(45), 1329-1352.

Bandura, A. (1977). Social learning theory. Prentice Hall: Englewood Clififs.

Barney, J. B., \& Hesterly, W. S. (2007). Administração estratégica e vantagem competitiva. São Paulo: Pearson Prentice Hall.

Belk, R. (2014). You are what you can access: sharing and collaborative consumption online. Journal of Business Research, 67(8), 1595-1600.

Bertero, C. O. (2011). Réplica 2 - O que é um ensaio teórico. Réplica a Francis Kanashiro Meneghetti. Revista de Administração Contemporânea - RAC, 15(2), 338-342.

Boava, D. L. T., Macedo, F. M. F., \& Sette, R. S. (2012). Contribuições do ensaio teórico para os estudos organizacionais. Anais do ENEO, 7, Curitiba, PR, Brasil.

Botsman, R., \& Rogers, R. (2011). O que é meu é seu: como o consumo colaborativo vai mudar o nosso mundo. Porto Alegre: Bookman.

Burnett, L. (2014). The sharing economy: where we go from here. Chicago: Leo Burnett Company.

Chase, C. (2015). Economia compartilhada. Como as pessoas e plataformas da Peers Inc. estão reinventando o capitalismo. São Paulo: HSM do Brasil.

Che Wel, C. A. B., \& Bojei, J. (2009). Determining relationship marketing instruments. The IUP Journal of Marketing Management, 8(3-4).

Collis, D., \& Montgomery, C. (1995, July-August). Competing on resources strategy in the 1990s. Harvard Business Review, 73(4), 118-128. 
Day, G. S. (1992). Marketing's contribution to the strategy dialogue. Journal of the Academy of Marketing Science, 20(4), 323-3293.

Drucker, P. F. (1986). Inovação e gestão. Lisboa: Editorial Presença, 1986.

Dubois, E., Schor, J., \& Carfagna, L. (2014). An emerging eco-habitus: the reconfiguration of high cultural capital practices among ethical consumers. Journal of Consumer Culture, 14(2), 158-178.

El-Ansary, A. (2006). Marketing strategy: taxonomy and frameworks. European Business Review, 18(4), 266-293.

Foss, N. J., \& Langlois, R. N. (1997). Capabilities and governance: the rebirth production in the theory of economic organization. Druid Working Paper n. 97-2. Copenhagen: Copenhagen Business School.

Fremstad, A. (2015). Online platforms for exchanging and sharing goods. Future Economy.

Frenken, K. (2017). Political economies and environmental futures for the sharing economy. Philosophical Transactions of the Royal Society, 375(2095).

Gansky, L. (2011). Mesh: porque o futuro dos negócios é compartilhar. Rio de Janeiro: Alta Books.

Grant, R. M. (1991). A teoria baseada em recursos da vantagem competitiva: implicações para a formulação da estratégia. California Management Review, 33(3), 114-135.

Gregory, A., \& Halff, G. (2017). Understanding public relations in the sharing economy. Public Relations Review, 43(1).

Heinrichs, H. (2013). Sharing economy: a potential new pathway to sustainability. Gaia, 22(4), 228-231.

Herbert, M., \& Collin-Lachaud, I. (2016, March). Collaborative practices and consumerist habitus: an analysis of the transformative mechanisms of collaborative consumption. Recherche et Applications en Marketing- RAM (English Edition), 32(1).

Jannesson, E., Nilsson, F., \& Rapp, B. (2014). Strategy, control and competitive advantage: case study evidence. Berlin Heidelberg: Springer.

Jones, P., Clarke-Hill, C., Comfort, D., \& Hillier, D. (2008). Marketing and sustainability. Marketing Intelligence \& Planning, 16(2), 123-130.

Kirzner, I. M. (1985). Discovery and the capital process. Chicago: The University of Chicago Press.

Kotler, P., Kartajaya, H., \& Setiawan, I. (2010). Marketing 3.0: as forças que estão definindo o novo marketing centrado no ser humano. Rio de Janeiro: Elsevier. 
Kretzer, J., \& Menezes, E. A. (2006). A importância da visão baseada em recursos na explicação da vantagem competitiva. Revista de Economia Mackenzie, 4(4), 63-87.

Krupinsk, C. (2016, janeiro). Entendendo a economia colaborativa e a economia compartilhada. Recuperado em 4 de janeiro, 2016, de https://consumocolaborativo.cc.

Kumar, V., Jones, E., Venkatesan, R., \& Leone, R. (2011). Is marketing oriented a source of sustainable competitive advantage or simply the cost of competing? Journal of Marketing, 75, 16-30.

Leite, J. B. D., \& Porsse, M. D. C. S. (2003). Competição baseada em competências e aprendizagem organizacional: em busca da vantagem competitiva. Revista de Administração Contemporânea - RAC, edição especial, 121-141.

Martin, C. J. (2016). The sharing economy: a pathway to sustainability or a nightmarish form of neoliberal capitalism? Ecological Economics, 121, 149-159.

Maurer, A. M.; Figueiró, P. S., Pacheco, S. A., Silva, V. S., \& Barcellos, M. D. (2015). Yes, We also can! O desenvolvimento de iniciativas de consumo colaborativo no Brasil. BASE - Revista de Administração e Contabilidade da Unisinos, 12(1), 68-80.

Meneghetti, F. K. (2011). O que é um ensaio teórico? Revista de Administração Contemporânea - RAC, 15(2), 320-332.

Morais Neto, S., Pereira, M. F., \& Moritz, G. O. (2012). Novo capitalismo: criação de valor compartilhado e responsabilidade social empresarial. Revista Pretexto, 13(3), 72-91.

Novel, A. S., \& Demailly, D. (2014). The sharing economy: make it sustainable. Paris: Institut du Développement Durable et des Relations Internationals.

Olson, M. J., \& Kemp, S. J. (2015, March). Sharing economy: an in-depth look at its evolution \& trajectory across industries. Piper Jaffray Investment Research.

Owyang, J., Tran, C, \& Silva, C. (2014). The collaborative economy: products, services, and market relationships have changed as sharing startups impact business models. To avoid disruption, companies must adopt the Collaborative Economy Value Chain. USA: Altimeter Group.

Paswan, A. K., Blankson, C., \& Guzman, F. (2011). Relationship in marketing channels and marketing strategy. European Journal of Marketing, 45(3), 311-333.

Peteraf, M. A. (1993). The cornerstones of competitive advantage: a resource-based view. Strategic Management Journal, 14, 179-191. 
Penrose, E. (1959). The theory of the growth of the firm. Oxford: Basil Blackwell.

Prahalad, C. K., \& Hamel, G. (1990, May-June). The core competence of the corporation. Harvard Business Review, 68(3), 79-91.

Prahalad, C. K. (2010). A riqueza na base da pirâmide - erradicando a pobreza com o lucro. Porto Alegre: Bookman, 2010.

Porter, M. E., \& Kramer, M. R. (2011). Criação de valor compartilhado. Harvard Business Review Brasil, 89(1), 21-33.

Pugliese, V. (2015, 8 de dezembro). Economia colaborativa na era do lowsumerism. InnovationInsider. Recuperado em 4 de janeiro, 2016, de http://innovationinsider.com.br.

Rifkin, J. (2016). Sociedade com custo marginal zero. São Paulo: Makron Books do Brasil.

Schor, J. (2016). Debating the sharing economy. Great transition iniciative, 2014. Recuperado em 13 de maio, 2016, de http://greattransition.org/publication/debating-the-sharing-economy.

Schumpeter, J. A. (1934). The theory of economic development. Cambridge: Harvard University Press.

Silva, M. E., Aguiar, E. C, Falcão, M. C, \& Costa, A., C., V. (2012). A perspectiva responsável do marketing e o consumo consciente: uma interação necessária entre a empresa e o consumidor. Organizações em Contexto, 8(16), 61-90.

Silva, M. E., \& Balbino, D. P. Criando vantagem competitiva sustentável: a responsabilidade socioambiental empresarial à luz da visão baseada em recursos. Revista Ibero-Americana de Estratégia, 12(1), 29-53.

Silveira, L. M., Petrini, M., \& Santos, A. C. M. Z. (2016). Economia compartilhada e consumo colaborativo: o que estamos pesquisando?. Revista de Gestão da USP - REGE, 23(4), 298-305.

Sousa Filho, J. M., Wanderley, L. S. O., Gómez, C. R. P., \& Farache, F. (2010). Strategic corporate social responsability management for competitive advantage. Brazilian Administration Review - BAR, 7(3), 294-309.

Srivastava, R. K., Fahey, L., \& Christensen, H. K. (2014). A visão baseada em recurso e o marketing: o papel de ativos baseado no mercado para ganhar vantagem competitiva. Estratégia Baseada em Recursos. 15 artigos clássicos para sustentar vantagem competitiva. Porto Alegre: Bookman.

Sundararajan, A. (2016). The sharing economy: the end of employment and the rise of crowd-based capitalism. Cambridge: The MIT Press. 
Teece, D. J., Pisano, G., \& Shuen, A. (1997). Firm capabilities, resources, and the concept of strategy. Working Paper. Berkeley: University of California/Center for Research on Management.

Teece, D. J. (2009). Dynamic capabilities and strategic management. Oxford University Press.

Toaldo, A. M. M., \& Luce, F. B. (2006). Estratégia de marketing: contribuições para a teoria em marketing. Revista de Administração de Empresas - RAE, 46(4), 25-35.

Vasconcelos, F. C., \& Cyrino, A. B. (2000). Vantagem competitiva: os modelos teóricos atuais e a convergência entre estratégia e teoria organizacional. Revista de Administração de Empresas - RAE, 40(4), 2037.

Viana, D. (2015). O furo do capitalismo. Página 22, edição 96. 